\title{
Why do governments end up with debt: short-run effects matter
}

\author{
Audrey Desbonnet, Thomas Weitzenblum ${ }^{\dagger}$
}

\begin{abstract}
This paper reconsiders the impact of public debt in an economy with heterogeneous households and incomplete markets to emphasize the short run effects of an increase in public debt. As compared to models that rest on steady states analysis, we show that the welfare gains of a public debt increase are substantially higher when transitional dynamics are accounted for. The additional debt issue allows for a temporary reduction in the income tax rate, which stimulates labor supply and generates an overshooting of the interest rate. The short-run gains create a temptation to deviate toward higher levels of debt. Debt increases continue to generate welfare gains even when debt is considerably higher than its long-run optimal level.
\end{abstract}

Keywords: Public debt, Transition, Precautionary saving JEL-code: E60, H60

${ }^{*}$ Department of Economics, University of Vienna. Email: audrey.desbonnet@univie.ac.at

${ }^{\dagger}$ University of Lille 2, EQUIPPE and PSE-CEPREMAP. E-mail: thomas.weitzenblum@univ-lille2.fr 


\section{Introduction}

The last decades have been characterized by a quick accumulation of public debt. In the OECD area, the ratio of public debt over GDP was equal to $59 \%$ in 1989 (OECD (2009)). In 2008, the latter was much higher: it amounted to 79\% (OECD (2009)). Yet, the optimal taxation literature predicts that governments should accumulate assets rather than issue debt. How can theory be reconciled with the observation that governments issue large amounts of debt? This paper sheds light on the liquidity-constraint loosening effect of public debt to explain why governments have a bias towards the accumulation of debt.

The seminal contribution of Ricardo (1951a, 1951b) has given rise to a rich theoretical literature on public debt. According to Barro (1979), the level of public debt is irrelevant for current debt issue: the government should issue debt only when government expenditures depart from their average value. Lucas and Stokey (1983) study the result of Barro (1979) in a Ramsey model where public debt is state-contingent. As in Barro (1979), the role of public debt is to smooth tax distortions over time. Chari, Christiano and Kehoe (1994) revisit the result of Lucas and Stokey (1983) in a model augmented to allow for capital accumulation and business cycles. Chari, Christiano and Kehoe (1994) show that the result of Lucas and Stokey (1983) continues to hold. The analysis of Aiyagari, Marcet, Sargent and Seppälä (2002) reconsiders the result of Lucas and Stokey (1983) in a model where the government cannot fully insure against aggregate shocks because of markets incompleteness. When the government has only access to one-period risk-free bonds, the long-run public debt is negative. Krusell, Martin and Rios-Rull (2006) relax the commitment assumption in the Lucas and Stokey (1983) model. In the absence of aggregate uncertainty, they find no bias in favour of debt accumulation. It appears that these different theories are not able to explain the high and increasing level of public debt of the recent decades.

However, these different analyses rest on the assumption that agents are perfectly insured against idiosyncratic income risk. This assumption has, since then, been challenged (Aiyagari(1994b)). Aiyagari and McGrattan (1998) depart from the representative-agent growth model by assuming that agents face income shocks. In this setup, they show that the optimal quantity of public debt is positive. A higher public debt enhances the liquidity by providing an additional means of smoothing consumption and loosens the borrowing constraint. That is why public debt is welfare enhancing. However, the welfare gains of a higher public debt are very low: the role for public debt is of minor importance. 
Moreover, Floden (2001) emphasizes that positive public debt effects vanish if transfers are used optimally. Here, we argue that the analysis provided by Aiyagari and McGrattan (1998) and Floden (2001) may underestimate the role of public debt. Their analyses do not take into account the liquidity-constraint loosening effect of public debt that operates in the short run. At the date of the debt increase, the additional resources obtained from the issue can, for instance, be redistributed through tax reductions. As some households in the economy would like to borrow, but are unable to do so, they are likely to increase their consumption in response to the temporary increase in disposable income (Daniel (1993), Heathcote (2005)).

In this paper, Floden's (2001) economy is extended to take into account the shortrun effects of public debt, that we capture by modelling explicitly the transition from one steady state toward another. Financial markets are incomplete and there is a large number of ex ante identical infinitely-lived agents. Agents differ in ability and face idiosyncratic labor income shocks. Labor supply is assumed to be endogenous. Households are subject to a proportional income tax. As private insurance markets are incomplete, agents, who cannot borrow, save for a precautionary motive (Aiyagari (1994a)). We recall one of Floden's (2001) results: when comparing steady states, the consumption gain of being at the optimal public debt to GDP ratio $(150 \%)$, instead of its benchmark level $\left(\frac{2}{3}\right)$, amounts to $0.123 \%$. We show that the consumption gain is much higher when the shortrun impact of public debt is taken into account. The consumption gain here amounts to $0.9 \%$. Moreover, the analysis shows that the temporary reduction in the income tax rate implied by the additionnal debt issue is not the only mechanism which explains why consumption gains are higher. Indeed, the temporary reduction in the income tax rate leads to a temporary increase in labor supply and a temporary interest rate overshooting which contributes to raise the consumption gain. These results lead us to question the relevance of the long-run optimal level of public debt. The existence of short-run gains creates an incentive to deviate toward higher levels of public debt and could make increases above the long-run optimum beneficial. We search for the ratio of debt to GDP such that no further upward deviation would be welfare improving and find that it is as high as $560 \%$.

The paper is organized as follows. Section 2 presents the model and the transitional dynamics definition. We discuss the calibration in section 3. In section 4, the optimal quantity of public debt and its distributional characteristics are determined. In section 5, we characterize the transitional path and compute the welfare gains of a higher ratio of public debt to GDP when short-run effects of public debt are taken into account. Section 
6 concludes.

\section{The model}

The economy is populated by a continuum of households, a representative firm and the government.

\subsection{The representative firm}

Each period, one good is produced by a representative firm which has a Cobb-Douglas production function. There is no aggregate risk and the production function writes:

$$
F\left(K_{t}, Z_{t} N_{t}\right)=K_{t}^{\alpha}\left(Z_{t} N_{t}\right)^{1-\alpha}
$$

where $t, K_{t}, N_{t}$, and $Z_{t}$ respectively denote the date, the aggregate stock of physical capital, the detrended aggregate labor supply in efficiency units and the labor productivity. $Z_{t}$ grows at the exogenous rate $g$, so we will write $Z_{t}=(1+g)^{t}$, given that the initial level of labor productivity is set to unity. Factor markets are competitive, so each factor earns its own marginal productivity:

$$
\begin{aligned}
& r_{t}=F_{K}\left(K_{t}, Z_{t} N_{t}\right)-\delta \\
& w_{t}=F_{N}\left(K_{t}, Z_{t} N_{t}\right)
\end{aligned}
$$

Given the homogeneity of degree 1 of the production function, a balanced growth path is possible, where $N_{t}$ and $r_{t}$ are both constant, and where $K_{t}$ and $w_{t}$ grow at the rate $g$.

\subsection{Households}

There is a continuum of infinitely-lived agents of unit mass. Each period, households receive capital, bonds and labor incomes. Households, who are born with permanently different abilities, face an idiosyncratic risk on their individual labor productivity. This shock $e_{t} \in E$ is governed by a Markov chain. Agents cannot borrow and there is no insurance markets against this risk. In order to smooth consumption, agents can only self insure, that is, accumulate (resp. deplete) assets when their labor productivity is high (resp. low). Labor supply $0<l_{t}<1$ is endogenous. This leads to the following asset evolution equation:

$$
a_{t+1}=a_{t}+\left(r_{t} a_{t}+e_{t} w_{t} l_{t}\right)\left(1-\tau_{t}\right)+T r_{t}-c_{t}
$$


where $a_{t}, T r_{t}, \tau_{t}$, and $c_{t}$ respectively denote the current level of financial wealth, lump-sum transfers from the government, the proportional income tax rate and consumption. Agents preferences are represented by a time additive expected intertemporal utility function, $U$ :

$$
U_{0}=E \sum_{t=0}^{\infty} \beta^{t} u\left(c_{t}, l_{t}\right)
$$

$\beta$ is the time discount factor and $u$ is the instantaneous utility function which writes:

$$
u\left(c_{t}, l_{t}\right)=\frac{c_{t}^{1-\rho} \exp \left[-(1-\rho) \zeta l_{t}^{1+\eta}\right]}{1-\rho}
$$

with $\zeta, \rho$, and $1 / \eta$ respectively a constant, the relative risk aversion and the labor-supply elasticity.

From here on, we detrend the relevant variables by the technical progress $Z_{t}$. Let us denote with a 'hat' any variable which is detrended in the following way: $\widehat{x}_{t}=\frac{x_{t}}{(1+g)^{t}}$. Specifically, we also impose: $\widehat{V}_{t}\left(\widehat{a}_{t}, e_{t}\right)=\frac{V_{t}\left(a_{t}, e_{t}\right)}{(1+g)^{(1-\rho) t}}$. The detrended program then writes:

$$
\begin{aligned}
& \widehat{V}_{t}\left(\widehat{a}_{t}, e_{t}\right)=\underset{\widehat{c}_{t}, \widehat{a}_{t+1}, l_{t}}{\operatorname{Max}}\left\{u\left(\widehat{c}_{t}, l_{t}\right)+\beta(1+g)^{(1-\rho)} E_{t}\left[\widehat{V}_{t+1}\left(\widehat{a}_{t+1}, e_{t+1}\right) /\left(\widehat{a}_{t}, e_{t}\right)\right]\right\} \\
& \text { subject to: } \\
& \left\{\begin{array}{l}
\widehat{c}_{t}+\widehat{a}_{t+1}(1+g)=\widehat{a}_{t}+\left(r_{t} \widehat{a}_{t}+e_{t} \widehat{w}_{t} l_{t}\right)\left(1-\tau_{t}\right)+\widehat{T r}_{t} \\
\widehat{a}_{t+1} \geqslant 0 \\
\widehat{c}_{t} \geqslant 0
\end{array}\right.
\end{aligned}
$$

In the stationary equilibrium, the various inputs in the agent program, namely $\widehat{w}_{t}, r_{t}, \tau_{t}$, and $\widehat{T r}_{t}$ are all constant, so that the time dependence can be dropped. The decision rules will be denoted $\widehat{c}_{t}\left(\widehat{a}_{t}, e\right), l_{t}\left(\widehat{a}_{t}, e\right)$ and $\widehat{a}_{t+1}\left(\widehat{a}_{t}, e\right)$ (resp. $\widehat{c}(\widehat{a}, e), l(\widehat{a}, e)$ and $\left.\widehat{a}^{\prime}(\widehat{a}, e)\right)$ in the dynamic version (resp. in the stationary one).

\subsection{The government}

The government issues public debt, taxes labor and capital income and operates transfers. His expenses -government spending, transfers and the interest payment of the current debt- match his revenues- tax collection and the net public debt issue:

$$
G_{t}+T r_{t}+r_{t} B_{t}=B_{t+1}-B_{t}+T_{t}
$$


where $G_{t}, T r_{t}, B_{t}$, and $T_{t}$ are respectively the public consumption, lump-sum transfers, the current stock of public debt ${ }^{1}$ and the tax revenues, defined as follows:

$$
T_{t}=\tau_{t}\left(N_{t} w_{t}+r_{t} A_{t}\right)=\tau_{t}\left(N_{t} w_{t}+r_{t}\left(K_{t}+B_{t}\right)\right)
$$

We assume that the policy instruments which the government chooses to impose are the following ${ }^{2}$ :

$$
\frac{G_{t}}{Y_{t}}=\gamma_{t}, \frac{T r_{t}}{Y_{t}}=\chi_{t}, \frac{B_{t}}{Y_{t}}=b_{t}
$$

The detrended version of the government budget constraint writes:

$$
\widehat{G}_{t}+\widehat{T r}_{t}+r_{t} \widehat{B}_{t}=(1+g) \widehat{B}_{t+1}-\widehat{B}_{t}+\widehat{T}_{t}
$$

\subsection{Definition of the equilibria}

In this section, we define both the stationary equilibrium and the transitional dynamics. Only the latter makes it possible to capture the short-run effects of a higher ratio of public debt to GDP.

\subsubsection{Stationary equilibrium}

In this economy, we will denote as stationary equilibrium an equilibrium where detrended variables are constant over time. Given a policy $\{\chi, \gamma, b\}$, the stationary equilibrium consists of the vector $\left\{\widehat{c}(\widehat{a}, e), \widehat{a}^{\prime}(\widehat{a}, e), l(\widehat{a}, e), \Lambda(\widehat{a}, e), \widehat{K}, N, \widehat{Y}, r, \widehat{w}, \tau\right\}$ where $\Lambda(\widehat{a}, e)$ is the probability measure of agents over the space state, or equivalently, the cross sectional distribution of agents. The stationary equilibrium is attained when this vector is such that:

- Given $r, \widehat{w}, \tau$ and $\widehat{T r}=\chi \widehat{Y}$, the decision rules $\left\{\widehat{c}(\widehat{a}, e), \widehat{a}^{\prime}(\widehat{a}, e), l(\widehat{a}, e)\right\}$ are solutions of the stationary version of program (1),

- $\Lambda(\widehat{a}, e)$ is the unique stationary distribution consistent with the previous decision rules,

\footnotetext{
${ }^{1}$ The time subscript for the stock of public debt refers to the date when debt will be paid back and not to the date of issue.

${ }^{2}$ The ratios are time-dependent because we will implement the transition from one equilibrium, characterized by certain values for these instruments, to another one. This notation then allows for any adjustment of the policy over time.
} 
- The labor and the capital market clear:

$$
\begin{aligned}
& \widehat{K}+\widehat{B}=\sum_{e \in E} \int \widehat{a} \Lambda(\widehat{a}, e) d \widehat{a} \\
& N=\sum_{e \in E} \int e l(\widehat{a}, e) \Lambda(\widehat{a}, e) d \widehat{a}
\end{aligned}
$$

- Factor prices verify:

$$
\begin{aligned}
& r=F_{\widehat{K}}^{\prime}(\widehat{K}, N)-\delta \\
& \widehat{w}=\frac{F_{N}^{\prime}(K, Z N)}{Z}=F_{N}^{\prime}(\widehat{K}, N)
\end{aligned}
$$

- The Government budget is balanced:

$$
(r-g) \widehat{B}=\widehat{T}-(\widehat{G}+\widehat{T r}) \Longleftrightarrow(r-g) b=\tau\left(1-\delta \frac{\widehat{K}}{\widehat{Y}}+r b\right)-(\gamma+\chi)
$$

\subsubsection{Transitional dynamics}

As we will compute the transition from one steady state to another, we need a theoretical characterization of more complex dynamics. Basically, we need, as a starting point, initial conditions, which fully describe the state of the economy -that is, the state of all the heterogeneous agents, and that of the government- at date $t=0$. Given these initial conditions, the transition consists of a path of all relevant variables, namely that of $r_{t}$, $\widehat{w}_{t}, \widehat{Y}_{t}, N_{t}, \widehat{K}_{t}, \widehat{B}_{t}, \widehat{T r}_{t}$, and $\tau_{t}$. The transition rests on these paths being consistent with the agents' decision rules, which are simply the time-variable solutions of program (1) -note that this program is not only relevant for stationary environments, but also for time-varying ones. In practice, not all of the above variables are mutually independent. The core of the transition can be summarized by only two vectors, $\left(r_{t}\right)_{t \geqslant 0},\left(N_{t}\right)_{t \geqslant 0}$. The paths of $\widehat{w}_{t}, \widehat{K}_{t}, \widehat{Y}_{t}, \widehat{B}_{t}$, and $\widehat{T r}_{t}$ can then be obtained. This leads us to the following definition of a transitional path:

Given initial conditions $\left\{\Lambda_{0}(.,),. \widehat{B}_{0}\right\}$, and given the time-vector of exogenous policy instruments $\left\{b_{t}, \chi_{t}, \gamma_{t}\right\}$, a dynamic rational expectation equilibrium consists of $\left\{\widehat{c}_{t}(\widehat{a}, e), \widehat{a}_{t}^{\prime}(\widehat{a}, e), l_{t}(\widehat{a}, e), \Lambda_{t}(\widehat{a}, e), r_{t}, \widehat{w}_{t}, \tau_{t}, \widehat{Y}_{t}\right\}$ such that:

- At any date $T$, given the vectors $\left\{\left(r_{t}\right)_{t \geqslant T},\left(\widehat{w}_{t}\right)_{t \geqslant T},\left(\tau_{t}\right)_{t \geqslant T},\left(\widehat{T r}_{t}=\chi_{t} \widehat{Y}_{t}\right)_{t \geqslant T}\right\}$, $\widehat{c}_{T}(\widehat{a}, e), \widehat{a}_{T+1}(\widehat{a}, e), l_{T}(\widehat{a}, e)$ are the decision rules obtained from program $(1)$, 
- At any date $T, \Lambda_{T+1}$ is derived from $\Lambda_{T}$ and the above decision rules,

- At any date $T$, the labor and the capital markets clear, that is:

$$
\begin{aligned}
N_{T} & =\sum_{e \in E} \int e l_{T}(\widehat{a}, e) \Lambda_{T}(\widehat{a}, e) d \widehat{a} \\
\widehat{K}_{T}+\widehat{B}_{T} & =\sum_{e \in E} \int \widehat{a} \Lambda_{T}(\widehat{a}, e) d \widehat{a}
\end{aligned}
$$

- At any date $T$, factor prices verify:

$$
\begin{aligned}
r_{T} & =F_{\widehat{K}}\left(\widehat{K}_{T}, N_{T}\right)-\delta \\
\widehat{w}_{T} & =F_{N}^{\prime}\left(\widehat{K}_{T}, N_{T}\right)
\end{aligned}
$$

- At any date $T$, the law of motion of the stock of public debt is:

$$
\left(\gamma_{T}+\chi_{T}\right) \widehat{Y}_{T}+r_{T} \widehat{B}_{T}=(1+g) \widehat{B}_{T+1}-\widehat{B}_{T}+\tau_{T}\left(\widehat{Y}_{T}-\delta \widehat{K}_{T}+r_{T} \widehat{B}_{T}\right)
$$

\section{Calibration}

The model period is the year. Since the calibration of the model is identical to Floden's (2001), we will only stress the major points. The productivity process is approximated with Tauchen's (1986) procedure. Wages are made up of two components, one permanent ability level, $\mu$, and one temporary component, $q . \mu$ is iid with mean zero and variance $\sigma_{\mu}^{2}$. The productivity process is defined as follows:

$$
\log \left(q_{t}\right)=\psi \log \left(q_{t-1}\right)+\varepsilon_{t}
$$

where $\psi$ is the degree of persistence of shocks and $\varepsilon \sim N\left(0, \sigma_{\varepsilon}\right)$.

Table 1 summarizes Floden's (2001) calibration.

Table 1: parameter values

\begin{tabular}{ccccccccccccc}
\hline \hline$\rho$ & $\beta$ & $\delta$ & $\gamma$ & $\alpha$ & $\eta$ & $\chi$ & $b$ & $g$ & $\zeta$ & $\psi$ & $\sigma_{\varepsilon}$ & $\sigma_{\mu}^{2}$ \\
\hline 1.5 & 0.9884 & 0.075 & 0.217 & 0.3 & 2 & 0.082 & $\frac{2}{3}$ & 0.0185 & 9.1449 & 0.9 & 0.21 & 0.34 \\
\hline \hline
\end{tabular}

According to this calibration, there are 14 different productivity levels, divided in 2 subsets $E_{1}=\left\{e^{1}, e^{2}, e^{3}, e^{4}, e^{5}, e^{6}, e^{7}\right\}$ and $E_{2}=\left\{e^{8}, e^{9}, e^{10}, e^{11}, e^{12}, e^{13}, e^{14}\right\}$. Half of the agents belongs to subset $E_{1}$, and the other half to $E_{2}$, and no transition between the 2 subset is possible. Each subset is ergodic. The productivity levels are: 


\begin{tabular}{ccccccc}
\hline \hline$e^{1}$ & $e^{2}$ & $e^{3}$ & $e^{4}$ & $e^{5}$ & $e^{6}$ & $e^{7}$ \\
\hline 0.135288 & 0.219024 & 0.354587 & 0.574056 & 0.929363 & 1.504585 & 2.435837 \\
$e^{8}$ & $e^{9}$ & $e^{10}$ & $e^{11}$ & $e^{12}$ & $e^{13}$ & $e^{14}$ \\
\hline 0.267042 & 0.432326 & 0.699911 & 1.133116 & 1.834449 & 2.969867 & 4.808044 \\
\hline \hline
\end{tabular}

\section{Steady-state optimality}

In this section, we briefly present the results from stationary equilibrium simulations. Our baseline corresponds to a public debt to GDP ratio equal to $\frac{2}{3}$. In the simulations, a single policy parameter is modified, namely the ratio $b=\frac{\widehat{B}}{\widehat{Y}}$. The welfare is computed using the utilitarian criterion, as follows:

$$
W=\sum_{e \in E} \int_{a \in A} \widehat{V}(\widehat{a}, e) \Lambda(\widehat{a}, e) d \widehat{a}
$$

For the gains or losses to be interpretable, we compute the percentage of consumption $x$ that agents in the baseline would need, in order to be indifferent with the policy change ${ }^{3}$. As in Floden (2001), the optimal ratio of public debt to GDP is $150 \%$ and the welfare gains amount to $0.123 \%$. The welfare differs according to the agents classes. We sort agents by their intertemporal welfare, and focus on the bottom $5 \%$ and top $5 \%$ percentiles of this distribution. We will call the former the poorest $5 \%$, and the latter, the richest $5 \%{ }^{4}$. While the richest $5 \%$ of agents experience a high increase in consumption which amounts to $3.68 \%$, the poorest $5 \%$ of agents undergo a decrease in consumption of $2.31 \%$.

The distributional properties of public debt are reported in Figure 1. The latter plots the individual consumption-equivalent variation in percentage points, when comparing

\footnotetext{
${ }^{3}$ We assume that the relative change in consumption leaves the leisure choice unchanged as Aiyagari and McGrattan (1998). For a given agent, with an expected utility $\widehat{V}(\widehat{a}, e)$, this implies that:

$$
\begin{aligned}
\widehat{V}(\widehat{a}, e) & =E_{0} \sum_{t \geqslant 0}\left[\beta(1+g)^{(1-\rho)}\right]^{t} u\left(\widehat{c}_{t}, l_{t}\right) \\
& \Longrightarrow E_{0} \sum_{t \geqslant 0}\left[\beta(1+g)^{(1-\rho)}\right]^{t} u\left((1+x) \widehat{c}_{t}, l_{t}\right)=(1+x)^{(1-\rho)} \widehat{V}(\widehat{a}, e)
\end{aligned}
$$

${ }^{4}$ Our classification, in terms of intertemporal welfare, does not correspond exactly to the distribution of asset holdings. Indeed, the welfare also depends on the current productivity level of the agent. Calling the bottom $5 \%$ "the poorest $5 \%$ " is therefore not fully correct, but we use this expression for an obvious reason of simplicity.
} 

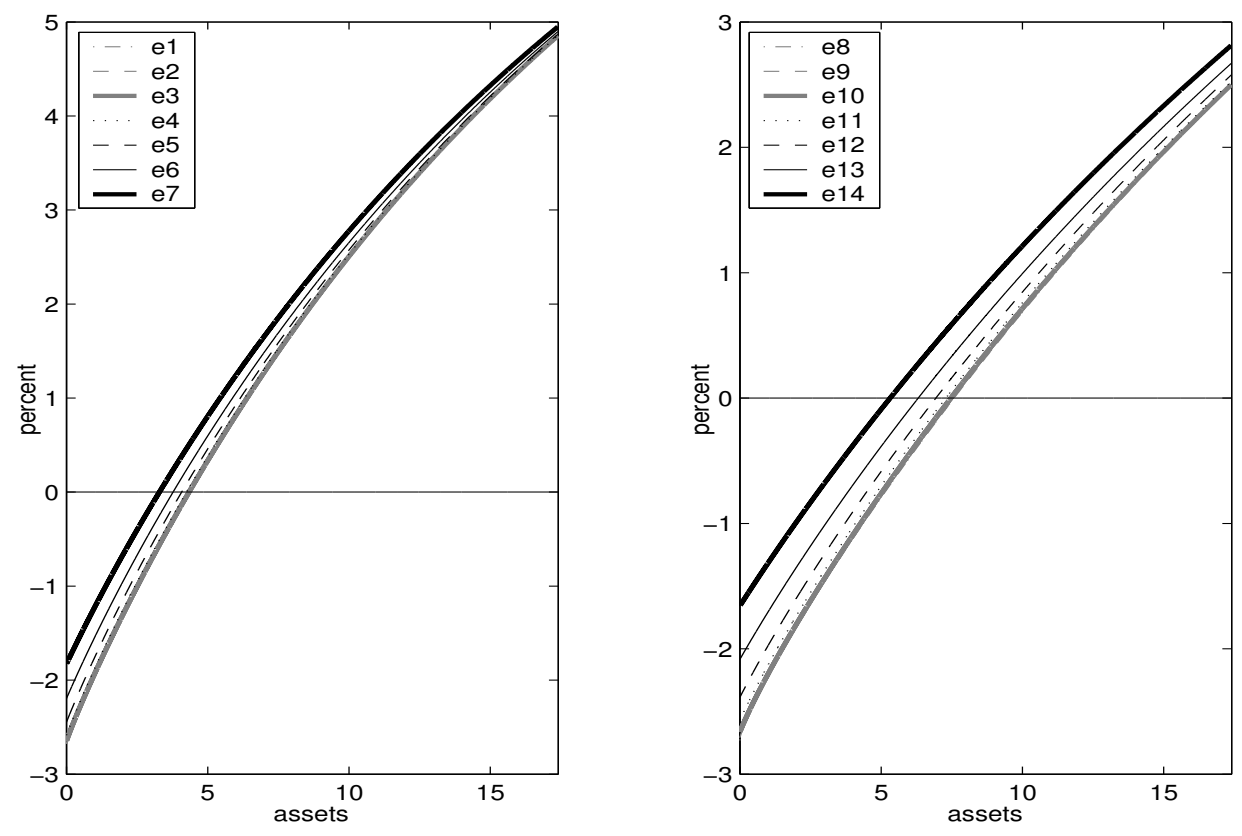

Figure 1: Consumption-equivalent variation by productivity level

the baseline $\left(b=\frac{2}{3}\right)$ with the optimal steady state $(b=1.5)$. Each individual state is characterized by the current level of financial wealth -on the horizontal axis- and by the level of productivity -one curve for each level. These figures reveal that the welfare changes are increasing in both the stock of assets and the productivity shock. The increasing pattern of the curve derives from the fact that the gain of a higher interest rate depends positively on the current stock of wealth. The welfare variations are positive only for asset stocks above a threshold (between 3.29 and 7.58, depending on the productivity level considered). Moreover, it turns out that $88.8 \%$ of the households are located below these thresholds. This is not inconsistent with the fact that the higher level of public debt yields a higher welfare; indeed, agents are richer with a higher public debt. This composition effect accounts for this apparent paradox.

Public debt affects the individual welfare levels through 3 channels: (i) it increases the income tax rate, (ii) it reduces the wage and (iii) it increases the interest rate. The first two effects act negatively on the individual well-being whereas the third one acts positively. The agents, whose productivity shock is low and/or assets holdings are low, are likely to suffer from increasing public debt. The agents, whose productivity shock is high and/or assets holdings, are likely to experience large gains from increasing public debt. 


\section{Optimality in the transition}

We here simulate the transition of the economy from a steady state, characterized by a given set of policy instruments, to another one. Our main motivation is to shed light on the liquidity-constraint relaxing effect of public debt in the short run. If public debt is increased at date $t=0$, it allows for an income tax rate reduction which should benefit liquidity constrained agents. Consequently, the analyses of Aiyagari et McGrattan (1998) and Floden (2001) do not capture the short-run gains associated with a higher ratio of public debt to GDP. The model simulations are intended to answer the following questions:

1. What are the order of magnitude of the short-run effects, omitted by Aiyagari et McGrattan (1998) and Floden ( 2001)?

2. What are the distributional characteristics of public debt on the transitional path, as compared to their steady-state counterpart?

3. Does the short-run welfare effects considerably alter the steady-state message regarding the optimal level of public debt?

\subsection{Simulations of the transitional dynamics}

The pre-reform (resp. the post-reform) public debt to GDP ratio will be denoted $b_{\text {init }}$ (resp. b). Although the model itself has already been fully described in the second section, some assumptions regarding the timing of the policy change are necessary. Precisely, we assume that the change pertains to the ratio of public to GDP, and is operated in $T_{\text {policy }}$ periods, from date $t=0$ to date $t=T_{\text {policy }}-1$. We assume that the public debt to GDP ratio is chosen to evolve linearly towards its final level:

$$
\begin{aligned}
& b_{t}=b_{\text {init }}+\frac{t}{T_{\text {policy }}-1}\left(b-b_{\text {init }}\right), \quad \text { for } t<T_{\text {policy }} \\
& b_{t}=b, \quad \text { for } t \geqslant T_{\text {policy }}
\end{aligned}
$$

The ratios $\gamma_{t}$ and $\chi_{t}$ are kept unchanged throughout the transitional path. We assume that the income tax rate adjusts to guarantee a balanced budget constraint. It therefore satisfies the following equations:

$$
\begin{aligned}
\tau_{0}=\frac{\left(\gamma_{0}+\chi_{0}\right) \widehat{Y}_{0}+\left(1+r_{0}\right) \widehat{B}_{0}-(1+g) b \widehat{Y}_{1}}{\left(\widehat{Y}_{0}-\delta \widehat{K}_{0}+r_{0} \widehat{B}_{0}\right)} & \\
\tau_{t}=\frac{\left(\gamma_{t}+\chi_{t}\right) \widehat{Y}_{t}+\left(1+r_{t}\right) b_{t} \widehat{Y}_{t}-(1+g) b_{t+1} \widehat{Y}_{t+1}}{\left(\widehat{Y}_{t}-\delta \widehat{K}_{t}+r_{t} \widehat{B}_{t}\right)} & \text { for } t \geqslant 1
\end{aligned}
$$


The difference between the two equations derives from the fact that, for $t \geqslant 1$, the level of debt is given by $\widehat{B}_{t}=b_{t} \widehat{Y}_{t}$. It is however not the case at date $t=0$; indeed, the level of debt represents the fraction $b_{i n i t}$ of the initial GDP $\widehat{Y}_{-1}$, but the GDP is not predetermined (because of the endogenous labor supply), which means that $\widehat{Y}_{0} \neq \widehat{Y}_{-1}$.

The date 0 welfare change, which takes full account of the short-run effects of the public debt, and which will be denoted as the transition-adjusted welfare change, is here again presented in percentage points of consumption. The baseline economy $\left(b=\frac{2}{3}\right)$ is chosen to be the initial steady state and the welfare of the whole population on the transitional path is measured at date $t=0$. Since this utilitarian criterion hides the diversity of the individual welfare adjustments, we also include the proportion of agents for whom the welfare is increased ${ }^{5}$ by the policy change in table 2 .

As the public debt to GDP ratio is switched from its initial level $\left(b_{\text {init }}=\frac{2}{3}\right)$ to its long-run optimal one $(b=1.5)$, we have set $T_{\text {policy }}$ at different values, ranging from 8 to 20. The table 2 presents the results ${ }^{6}$.

Table 2: Transition-adjusted welfare change

\begin{tabular}{ccccc}
\hline \hline & \multicolumn{4}{c}{$b_{\text {init }}=\frac{2}{3} \rightarrow b=1.5$} \\
\cline { 2 - 5 } & \multicolumn{4}{c}{ Steady State } \\
\cline { 2 - 5 } & Average & Top $5 \%$ & Bottom $5 \%$ & $\%$ of agents \\
& $0.123 \%$ & $3.68 \%$ & $-2.31 \%$ & $/$ \\
\cline { 2 - 5 } & Average & Top $5 \%$ & Bottom $5 \%$ & $\%$ of agents \\
$T_{\text {policy }}=8$ & $0.909 \%$ & $2.971 \%$ & $0.196 \%$ & $92.37 \%$ \\
$T_{\text {policy }}=12$ & $0.915 \%$ & $2.694 \%$ & $0.345 \%$ & $97.60 \%$ \\
$T_{\text {policy }}=16$ & $0.904 \%$ & $2.472 \%$ & $0.425 \%$ & $98.74 \%$ \\
$T_{\text {policy }}=20$ & $0.885 \%$ & $2.283 \%$ & $0.471 \%$ & $99.55 \%$ \\
\hline \hline & Note: The increase in $b$ is operated in $T_{\text {policy }}$ periods
\end{tabular}

The welfare gains are much larger when short-run effects are taken into account. The poorest $5 \%$ of agents do not undergo a decrease in consumption anymore. It can be noticed that the wealthiest agents are better off, the lower $T_{\text {policy }}$, while the reverse applies for the poorest ones. This follows from the nature of the gains for these different agents. For the richest $5 \%$, the gains are driven both by their high level of asset holdings and by their

\footnotetext{
${ }^{5}$ that is those for whom the individual percentage change of consumption is positive.

${ }^{6}$ We have not calculated the proportion of agents favoring the policy shock through steady state comparisons because different steady states imply different distribution of agents. For example, the poorest $5 \%$ for $b_{\text {init }}=2 / 3$ are not the same as the poorest $5 \%$ when $b=1.5$. Moreover, comparing steady states means that we only consider long-run equilibria, and in the long-run, all agents are ex ante alike.
} 
high current wage. Because of the Markovian structure of the individual productivity shocks, which is characterized by the regression-towards-the mean property, these agents are likely to be hit by a negative productivity shock in the near future, bringing their wage closer to the average one. It is in their interest that the income tax rate reduction be as high and as short-lived as possible. Conversely, as $T_{\text {policy }}$ increases, the expected gains from a public debt increase would then be lower, as the reduction of the income tax rate would be of a lesser magnitude, and over a longer time spell. Regarding the poorest $5 \%$, their current wage is very low, and they hardly own any financial assets. The income tax rate reduction would not be so beneficial at date 0 , precisely because their current labor supply is rather low.

The next section addresses the second question. A particular transition is more thoroughly analyzed, and the distributional properties of a public debt increase are brought into light.

\subsection{Zooming in on a particular transitional path}

The previous results have shown that a non-negligible gain, in terms of utilitarian criterion, is to be expected from such a policy change. We intend to better understand the macroeconomic adjustment in the short run and the distributional impact of the policy shock. In particular, we wish to single out the liquidity-constraint relaxing effect, and possibly other short-run effects which were not thought of in the first place.

We here present more detailed results for the transitional path characterized by an initial public debt to GDP ratio $b_{\text {init }}=\frac{2}{3}$, and a final public debt to GDP ratio $b_{t}=0.8$ for $t \geqslant 1$, with $T_{\text {policy }}=1$. Transition-adjusted welfare gains and welfare gains based on steady-state comparison are reported in Table 3.

\begin{tabular}{lcc}
\multicolumn{3}{c}{ Table 3: Transition-adjusted welfare change } \\
\hline \hline$b_{\text {init }}=\frac{2}{3} \rightarrow b=0.8$ & Steady State & Transition \\
\cline { 2 - 3 } average & $0.0384 \%$ & $0.176 \%$ \\
top 5\% & $0.610 \%$ & $0.605 \%$ \\
bottom 5\% & $-0.420 \%$ & $0.022 \%$ \\
\% of agents & $/$ & $89.20 \%$ \\
\hline \hline
\end{tabular}

Transition-adjusted welfare gains are 4.5 times higher than welfare gains based on steady-state comparison. The $5 \%$ poorest of agents do not experience welfare loss anymore. The welfare gain for the $5 \%$ richest is roughly equivalent, whether the transition is taken into account, or not. 
The graphs 2 plot the paths of the stock of capital, the interest rate, the tax rate, the
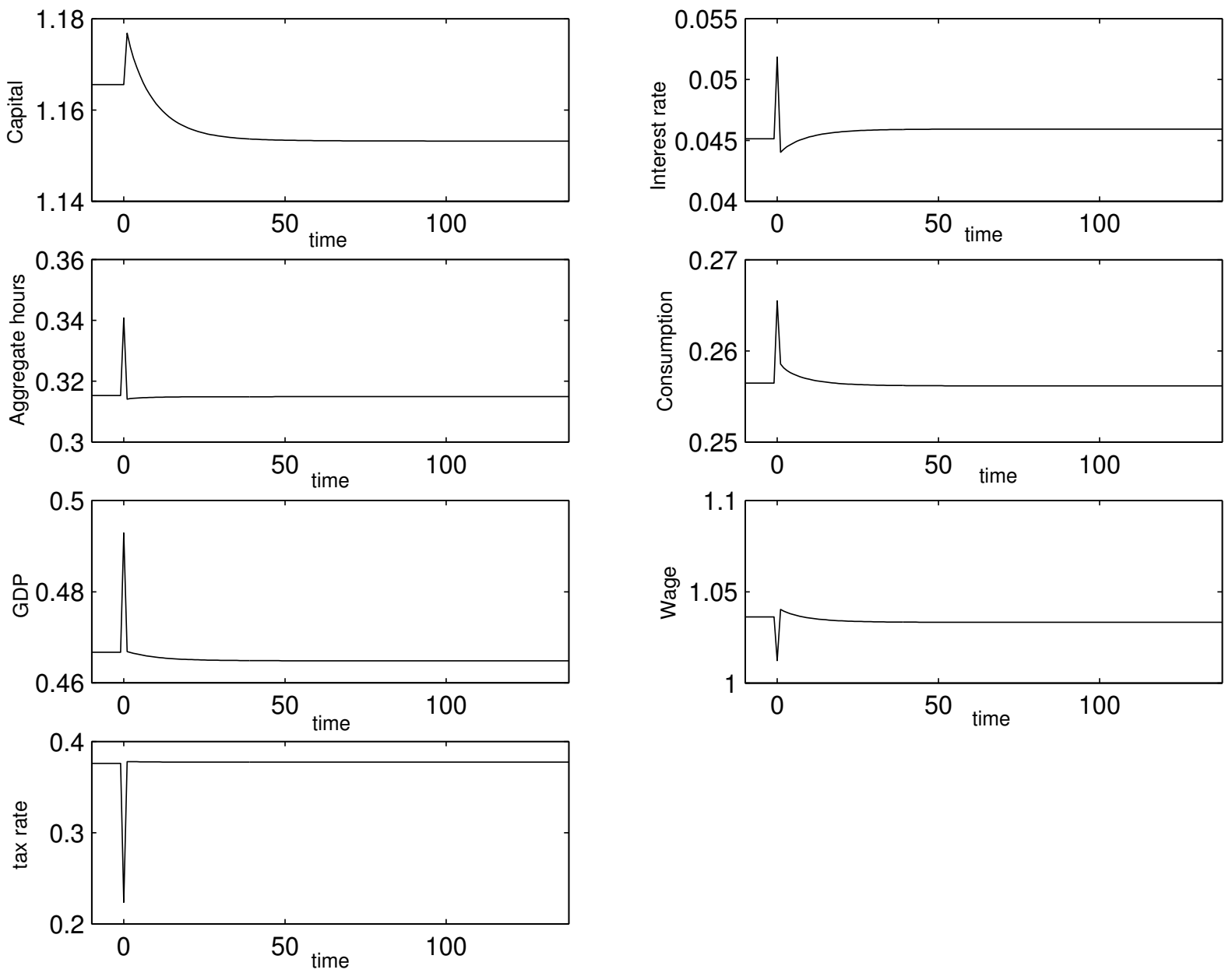

Figure 2: The dynamics of the economy in the baseline model

The labor supply instantly jumps from 0.3153 to 0.3408 . The intertemporal substitution effect accounts for the large increase in labor supply at date $t=0$. As hours worked are less heavily taxed, households want to work more. From $t=1$ onwards, labor supply is brought back to a considerably lower level, close to its final one. This increase in labor supply explains the non-monotonic path of the interest rate ${ }^{7}$. It first increases substantially at date $t=0$ (a $14.91 \%$ increase, or equivalently, a 0.67 percentage point increase),

\footnotetext{
${ }^{7}$ Note that the increase in public debt is only effective at the end of date 0 (with our convention, it refers to date $t=1$ ). Therefore, both the beginning-of-period financial wealth of households, and the
} 
then falls sharply at date $t=1$. From $t=1$ onwards, it progressively re-increases to reach its final steady-state level and the main determinant of the interest rate is then the household capital supply. The increase in labor supply accounts for the considerable increase in GDP of $5.60 \%$ at date $t=0$. Therefore, the increase in saving at the end of date $t=0$ is not driven only by the temporary reduction in income tax rate (which amounts to $40.51 \%$, or 15.2 percentage point), but also by the increase in gross income. It then explains why the interest rate drops so much at date 1 (the decrease amounts to $15.11 \%$, or 0.78 percentage point): the labor supply is no longer above its initial level, while the stock of capital is considerably increased. Capital increases from $t=0$ to $t=1$, by $0.964 \%$, and then reverts back to its new long-run level. Consumption at date $t=0$ instantly increases and then diminishes. It can be observed that consumption does not seem fully continuous between dates 0 and 1 (although the deviation from a continuous graph is very modest). This is due to the fact that the consumption and labor supply choices are mutually dependent. The higher the labor supply, the higher the marginal utility of consumption, as the equation below shows:

$$
u_{c_{t}}^{\prime}=c_{t}^{-\rho} \exp \left[-(1-\rho) \zeta l_{t}^{1+\eta}\right] \Longrightarrow \frac{\partial u_{c_{t}}^{\prime}}{\partial l_{t}}=\underbrace{-(1+\eta)(1-\rho)}_{>0 \text { if } \rho>1} l_{t}^{\eta} c_{t}^{-\rho} \exp \left[-(1-\rho) \zeta l_{t}^{1+\eta}\right]
$$

This property rests on the relative risk aversion $\rho$ being greater than unity. In such a case, the consumption and labor supply choices seem complementary. The more agents work, the more willing they are to consume. Since the labor supply is much higher at date $t=0$ than at any other date, it follows that there is an additional motive to consume ${ }^{8}$.

The differentiated impact of the policy change on the heterogeneous households is presented on Figure 3. The latter plots the welfare change, measured at date $t=0$, as a function of the current asset holdings, for the 14 different levels of productivity. The asset axis has been scaled so that its maximum corresponds to the richest agents in the initial stationary distribution. Yet, half (resp. 75\%) of the households hold less than 0.78 (resp. 2) units of assets. Unlike the analysis based on the steady-state comparison, the welfare gains are characterized by a U-shape, for all productivity levels. For productivity shocks $e^{2}, e^{3}, e^{8}$ and $e^{9}$ (which correspond to low productivity shock) the welfare variation is first positive for those whose financial assets level is respectively less than 0.0088, 0.0753,

public debt $\widehat{B}_{0}$, are predetermined. With the convention adopted, all income flows are end-of-period, which means that the capital supply is totally predetermined at date $t=0$. The increase in the interest rate is then fully driven by the increase in the labor supply.

${ }^{8}$ Note that, as we have illustrated just above, this does not prevent households from saving considerably at the end of date $t=0$. 
0.0496 and 0.1359 , then negative, and positive again (for those whose financial assets level is respectively higher than $1.7771,1.1788,3.2067$ and 2.6292). The other productivity shocks experience a welfare gain regardless of the level of financial assets. It was not the case when the calculation of the welfare gains did not take the short-run effects into account.
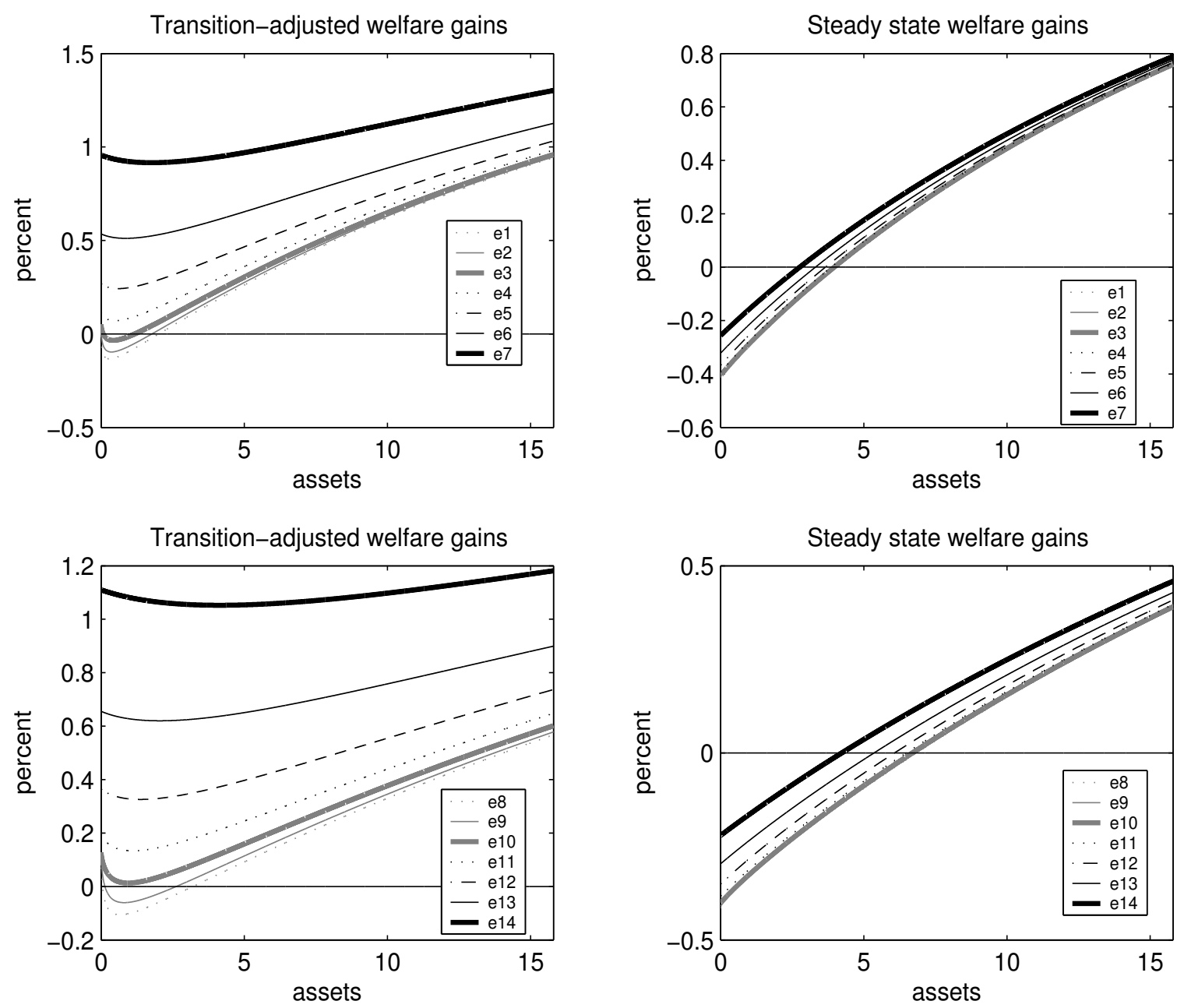

Figure 3: Consumption-equivalent variation by productivity level at date $t=0$

The time path of the income tax rate, of the labor supply, of the interest rate and of the wage, account for the differentiated welfare impact of the reform. Part of the gain is derived from the income tax rate reduction at date $t=0$. Other things being equal, the decrease in the tax rate at date $t=0$ should benefit more

(i) households who are close to the liquidity constraint as it increases their disposable 
income

(ii) households who are currently hit by a high productivity shock as it decreases the after-tax wage

(iii) households who hold a large amount of financial assets. The larger financial wealth, the larger the after-tax capital income for any given productivity level.

The pure liquidity-relaxing effect (channel (i)) can be easily singled out from these graphs. Indeed, all curves are initially downward sloping, implying that the gain, measured in consumption equivalent, is higher, the lower current asset holdings. Households with no wealth and the lowest productivity undergo a welfare loss of $0.413 \%$ when shortrun effects are not taken into account. The welfare loss is significantly reduced when short-run effects are taken into account. The welfare loss is barely negative, equal to $0.008 \%$. Channel (ii) appears very clearly in the graph. For any given level of assets, the higher the productivity, the higher the welfare gain curve. Finally, Channel (iii) explains why all curves are upward sloping, for high levels of assets.

\subsection{Transfer adjustment at date 0}

For anyone who has in mind the potentially powerful liquidity-relaxing effect of public debt, the previous results may not be so compelling and may well be attributable to the type of fiscal adjustment chosen at date $t=0$. Instead of reducing the income tax rate, the budgetary surplus can also be redistributed to agents in many other ways. Among them, lump-sum transfers should operate a significant redistribution. Therefore, we here consider the case where the initial income tax rate $\tau_{0}$ remains equal to its pre-reform value, and where initial transfers endogenously adjust. The government budget constraint at date 0 then implies:

$$
\widehat{T r}_{0}=(1+g) b \widehat{Y}_{1}-\left(1+r_{0}\right) \widehat{B}_{0}+\tau_{0}\left(\widehat{Y}_{0}-\delta \widehat{K}_{0}+r_{0} \widehat{B}_{0}\right)-\gamma \widehat{Y}_{0}
$$

The transition bears on a public debt to GDP ratio increase from $b_{\text {init }}=\frac{2}{3}$ to $b=0.8$, as was the case in the previous section. The figure 4 plots the time-profile of the capital, the interest rate, aggregate hours, consumption, GDP and the wage, when the initial adjustment is operated through taxes (baseline) and when it is operated through transfers (TR).

The time-profiles are qualitatively quite different from their baseline counterparts. The path of capital is almost smooth. The labor supply slightly diminishes at date $t=0$ and remains smooth afterwards. This accounts for the slight decrease in the interest 

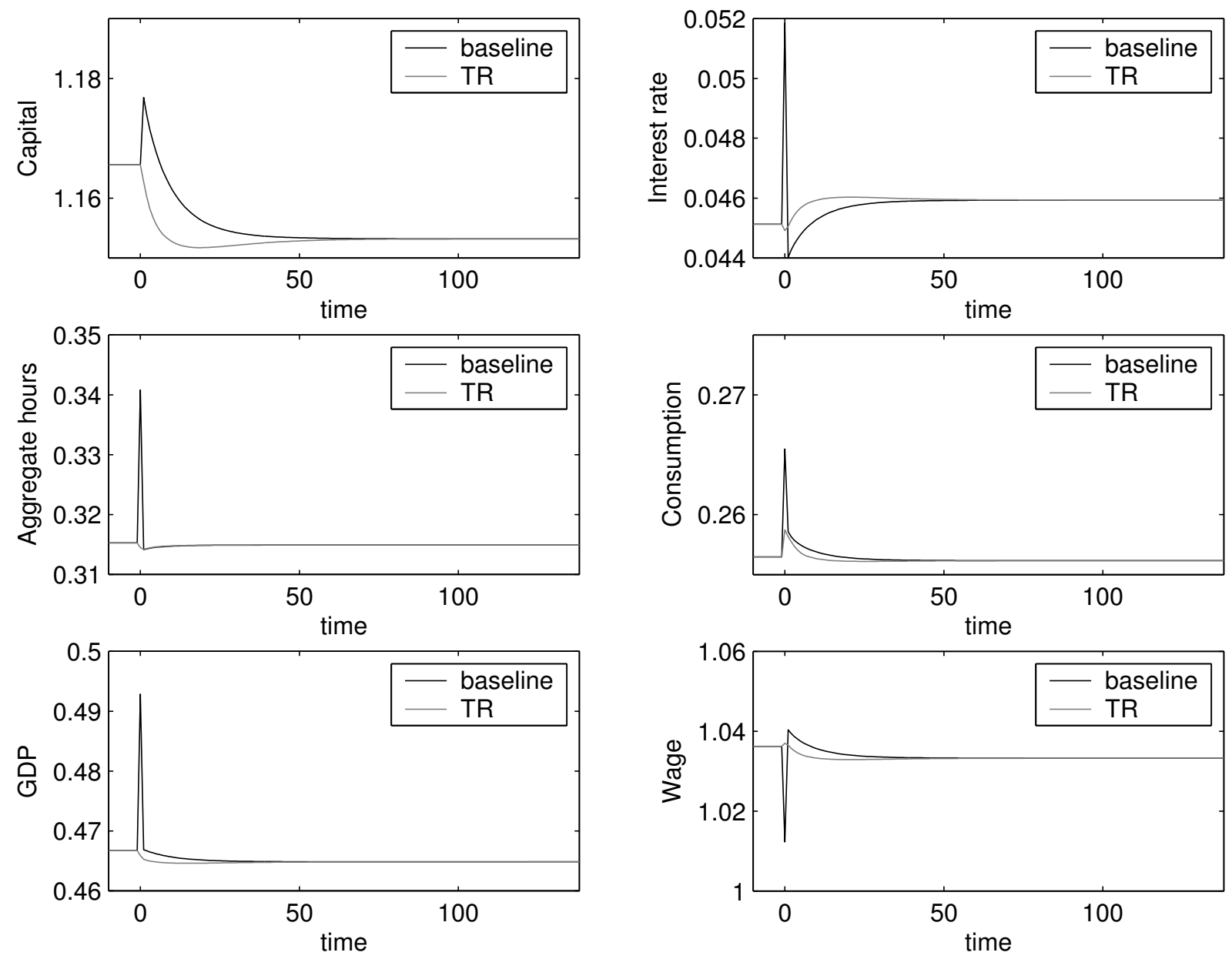

Figure 4: The dynamics of the economy when a lump-sum transfer is operated

rate at date $t=0$. From date $t=1$ onwards, the path of the interest rate is smooth. Consumption increases at date $t=0$ on account of the temporary increase in the lumpsum transfer. However, the increase at date $t=0$ is much lower than in the baseline case because the labor supply does not increase at date $t=0$. Moreover, consumption remains lower during the first 40 periods in the lump-sum transfer setting. This result illustrates the high and persistent effect of the initial increase in labor supply in the case of the temporary income tax rate reduction. The transition-adjusted welfare change are presented in table 4 when the budgetary surplus is redistributed in the form of a lump-sum transfer.

The welfare gains are different when the budgetary surplus is redistributed through 
Table 4: Transition-adjusted welfare change when there is a lump-sum transfer

\begin{tabular}{|c|c|c|c|}
\hline \multirow{2}{*}{$b_{\text {init }}=\frac{2}{3} \rightarrow b=0.8$} & \multirow[b]{2}{*}{ Steady State } & Baseline & Lump-sum transfer \\
\hline & & Transition & Transition \\
\hline average & $0.0384 \%$ & $0.176 \%$ & $0.381 \%$ \\
\hline top $5 \%$ & $0.610 \%$ & $0.605 \%$ & $0.263 \%$ \\
\hline bottom $5 \%$ & $-0.420 \%$ & $0.022 \%$ & $1.154 \%$ \\
\hline$\%$ of agents & / & $89.20 \%$ & $100 \%$ \\
\hline
\end{tabular}

lump-sum transfers. As we expected, the gains are much higher for the poorest agents and lower for the richest ones. What may seem less obvious is that the utilitarian criterion increases considerably more here: it amounts to $0.381 \%$. The welfare gains are twice as high as those in the baseline case $(0.176 \%)$. As compared to the steady state calculation, the gain is now 10 times higher. Besides, all agents gain from this policy shock, while a significant minority of agents opposed the income tax rate reduction.

The differentiated welfare effects are shown on Figures 5 and 6 . The consumption variations (labelled Tr) are compared with the transition-adjusted consumption variations of the baseline model (labelled baseline). We also report the corresponding consumption variations computed from steady state (ss) comparisons. For the productivity levels $e^{1}$, $e^{2}, e^{3}, e^{4}, e^{5}, e^{8}, e^{9}$ and $e^{10}$-that is, the low productivity levels-, the consumption variation curve displays a "U" pattern. The decreasing part of the curve captures the welfare gain due to the liquidity-relaxing effect of the temporary increase in the lump-sum transfer. It is higher than in the baseline case. When asset holdings are higher, the welfare gain becomes smaller than in the baseline case. This is due to the fact that rich agents do benefit from a capital income tax rate reduction in the baseline case, while they do not in this scenario.

For productivity levels $e^{6}, e^{7}, e^{11}, e^{12}, e^{13}$ and $e^{14}$, the welfare gain is lower than in the baseline case, regardless of the financial asset level. Indeed, their disposable income would raise more significantly if an income tax rate reduction were implemented.

This comparison corroborates the intuition that the type of fiscal adjustment at date $t=0$ has a considerable impact on how poor agents might, or might not, benefit from the public debt increase. 

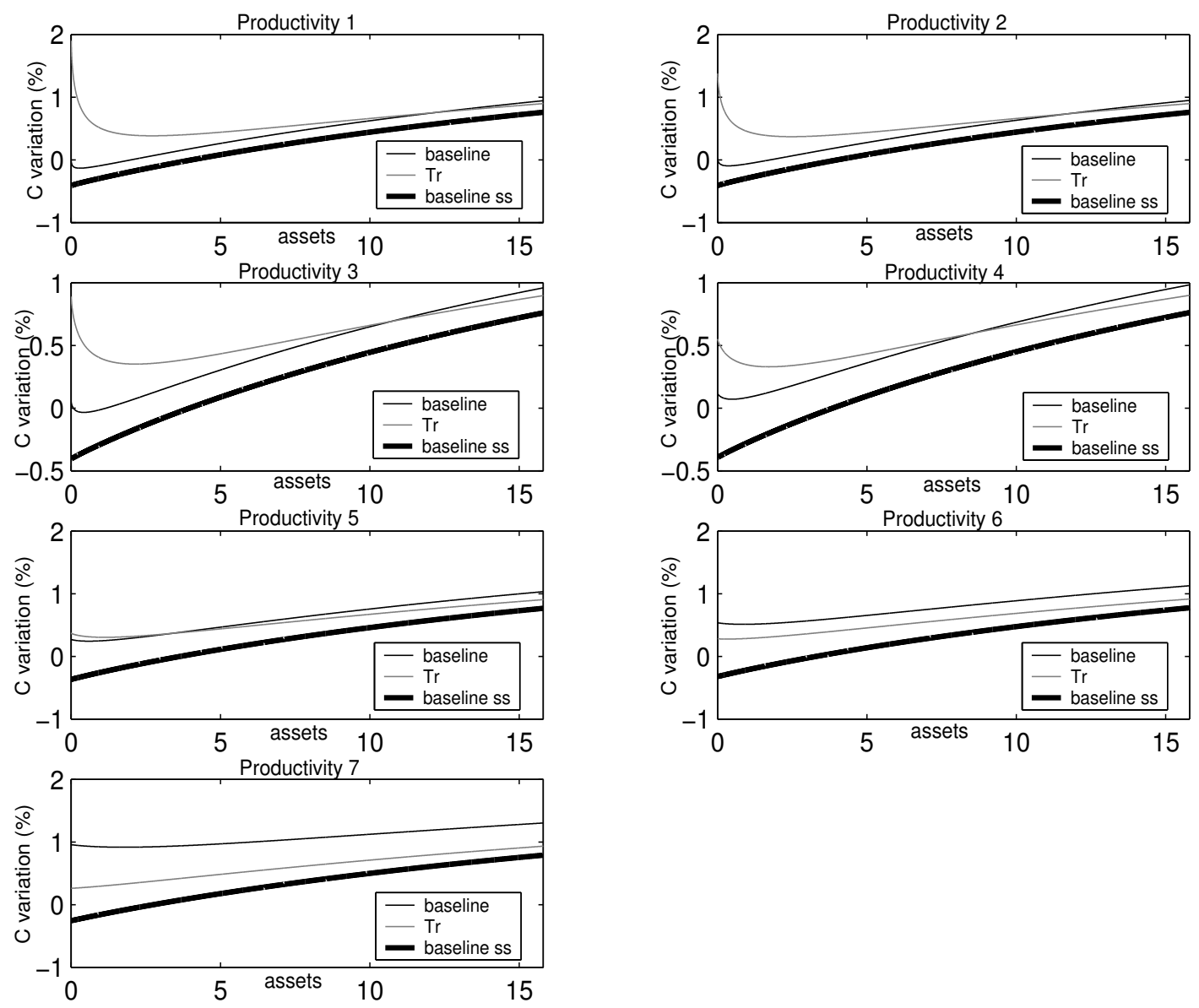

Figure 5: Consumption-equivalent variation by productivity level (from level 1 to level 7) when a lump-sum transfer is operated

\subsection{Transition-adjusted optimality and equilibrium}

The previous simulations have shown that (i) a progressive transition towards the longrun optimal level yields significant welfare gains and that (ii) considerable transitional adjustments operate in the short run. We could then wonder whether the short-run gains arising when debt is increased could not make further increases of the public debt to GDP ratio, above its long-run optimal level, beneficial. It is clear that long-run costs will emerge, but it is much less clear whether they should necessarily dominate the short-run gains.

To perform this exercise, we have simulated a $10 \%$ increase, starting with steady states associated with various public debt to GDP ratios. Whenever the policy shock generates gains according to the utilitarian criterion, the initial public debt to GDP does 

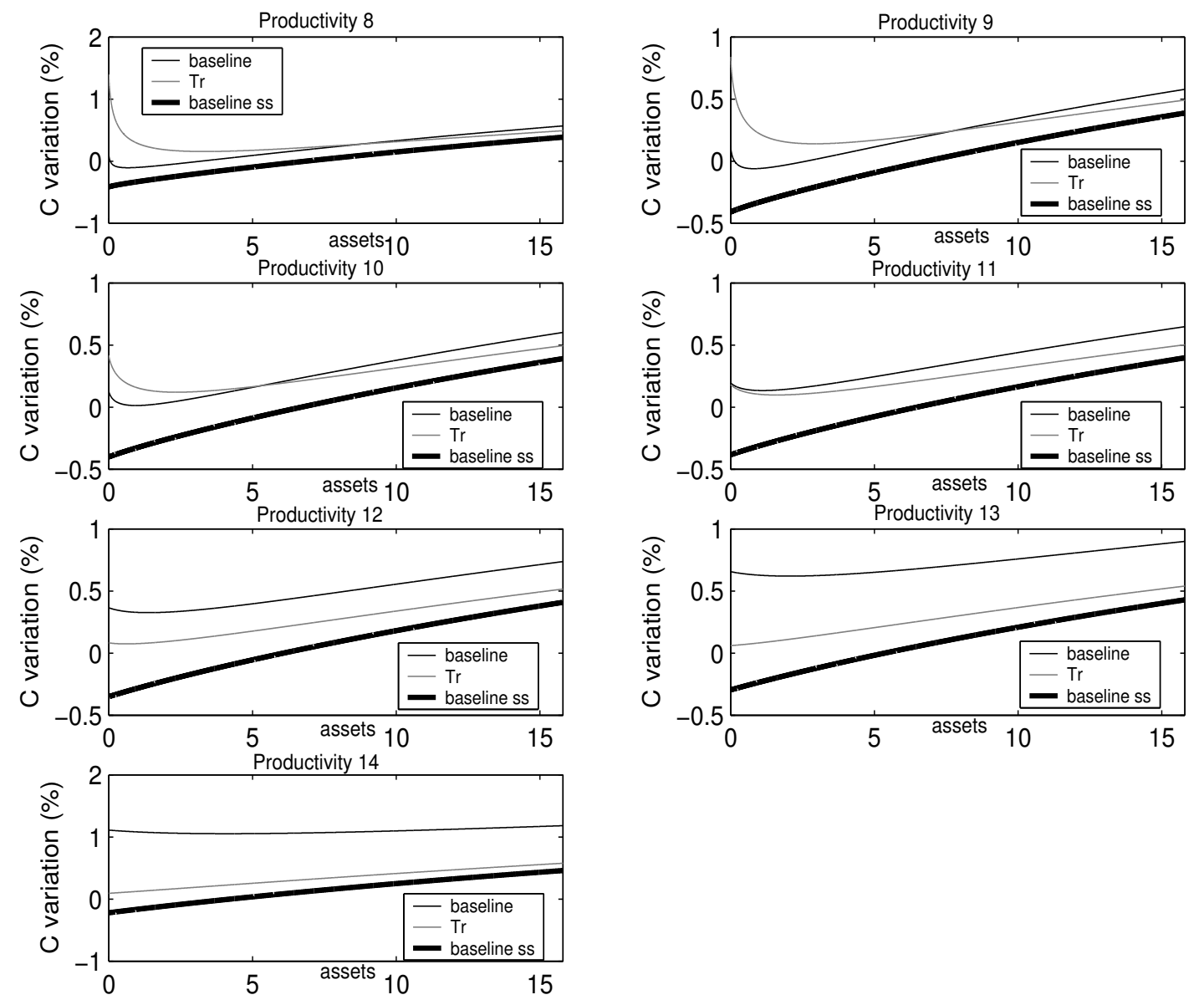

Figure 6: Consumption-equivalent variation by productivity level (from level 8 to level 14) when a lump-sum transfer is operated

not correspond to the highest utilitarian criterion. Table 5 presents, for various initial public debt to GDP ratios $b_{\text {init }}$, the welfare change implied by a 10 percentage points increase in the public debt to GDP ratio. The proportion of households for whom the intertemporal utility increases is reported in the table 5 too.

It appears that a majority of agents favors debt increases until it reaches $390 \%$. In terms of the utilitarian criterion, gains cease to occur for a level as high as $560 \%$. The equilibrium level of debt derived from the majority voting criterion is significantly lower than its utilitarian counterpart. The analysis has shown that the gains obtained by rich agents can be quite high, while the losses (the minimum on the 'U' curves) are lower, in absolute value. Therefore, when the majority criterion equilibrium has been reached $(390 \%)$, the proportions of winners and losers are equal. However, the gain of the winners 
Table 5: Transition-adjusted welfare change

\begin{tabular}{ccc}
\hline \hline change in public debt & Utilitarian welfare criterion & proportion of households \\
\hline$b_{\text {init }}=1.9 \rightarrow b=2.0$ & $0.079 \%$ & $74.26 \%$ \\
$b_{\text {init }}=2.9 \rightarrow b=3.0$ & $0.049 \%$ & $58.05 \%$ \\
$b_{\text {init }}=3.6 \rightarrow b=3.7$ & $0.033 \%$ & $51.04 \%$ \\
$b_{\text {init }}=3.8 \rightarrow b=3.9$ & $0.029 \%$ & $\mathbf{5 0 . 1 7} \%$ \\
$b_{\text {init }}=3.9 \rightarrow b=4.0$ & $0.026 \%$ & $49.81 \%$ \\
$b_{\text {init }}=4.9 \rightarrow b=5.0$ & $0.009 \%$ & $48.14 \%$ \\
$b_{\text {init }}=5.5 \rightarrow b=5.6$ & $\mathbf{0 . 0 0 0 3} \%$ & $47.69 \%$ \\
$b_{\text {init }}=5.6 \rightarrow b=5.7$ & $-0.001 \%$ & $47.62 \%$ \\
\hline \hline
\end{tabular}

are higher than the losses of the losers. That is why further increases induce intertemporal welfare gains.

These simulations shed light on the significant temptation to deviate toward a ratio of public debt to GDP of $560 \%$, in order to capture short-run gains. This figure is, of course, very high, and higher than its empirical counterpart ${ }^{9}$. In our model, there is no aggregate government expenditure shock. Therefore, the government has no tax smoothing motive. In an environment where government faces aggregate government expenditure shocks and has only access to a risk-free one-period asset ${ }^{10}$, the government accumulates assets to minimize tax distortion in the long run (Aiyagari, Marcet, Sargent and Seppälä (2002)). Consequently, the ratio of public debt to GDP would be lower in an environment where the precautionary saving motives of the government and households are taken into account.

\section{Conclusion}

The purpose of this study is to highlight the liquidity-constraint loosening effect of public debt which contributes to explain why governments end up in debt. We extend Floden's economy (2001) to describe explicitly the short-run effects resulting from a public debt increase. It turns out that consumption gains are considerably higher when short-run effects of public debt are taken into account. Moreover, the analysis suggests that the higher consumption gains are not only due to the temporary decrease in the income tax rate. The increase in the ratio of public debt to GDP leads to an increase in labor supply which, in turn, is responsible for an interest rate overshooting.

The existence of short-run gains create a temptation to deviate from the long-run

\footnotetext{
${ }^{9}$ The U.S. ratio of public debt to GDP amounted to $75 \%$ in 2008 (OECD (2009)).

${ }^{10}$ which means that insurance markets are incomplete.
} 
optimal debt to GDP ratio. It appears that a benevolent government, following the utilitarian criterion, is tempted to increase the ratio of public debt to GDP up to $560 \%$. This figure is higher than its empirical counterpart. This analysis does not take the tax smoothing motive of the government into account, as government spendings are assumed to be constant. Moreover, this exercise ignores important issues related to the definition of the optimal level of public debt: why should the government implement a once-and-for-all policy change, and why not consider more sophisticated time-pathes for the debt to GDP ratio? How a truly time-consistent behavior of the government could alter this message? The goal of this study is to stress the importance of the liquidity-constraint loosening effect of public debt, so that these questions are left for future research. 


\section{References}

[1] Aiyagari, S.R., 1994a, Uninsured idiosyncratic risk and aggregate saving, Quarterly Journal of Economics, 109, 659-684

[2] Aiyagari, S.R., 1994b, Macroeconomics with frictions, Federal Reserve Bank of Mineapolis Quarterly Review, 18, 24-40

[3] Aiyagari, R., McGrattan, R.E., 1998, The Optimum quantity of debt, Journal of Monetary Economics, 42, 447-469

[4] Aiyagari, S. R., Marcet, A., Sargent, T. J., Seppälä, J., 2002, Optimal taxation without state-contingent debt, Journal of Political Economy, 110, 1220-1254

[5] Auerbach, A.J., Kotlikoff, L.J., 1987, Dynamic Fiscal Policy, Cambridge University Press

[6] Barro,R.J., 1979, On the determination of the public debt, Journal of Political Economy, 87, 940-971

[7] Chari, V.V., Christiano, L.J., Kehoe, P.J., 1994, Optimal fiscal policy in a business cycle model, Journal of Political Economy, 102, 617-652

[8] Daniel, B.C., 1993, Tax Timing and Liquidity Constraints: A Heterogeneous-Agent Model, Journal of Money, Credit and Banking, 25, 176-196

[9] Floden, M., 2001, The effectiveness of government debt and transfers as insurance, Journal of Monetary Economics, 48, 81-108

[10] Heathcote, J., 2005, Fiscal Policy with Heterogeneous Agents and Incomplete Markets, Review of Economics Studies, 72, 161-188

[11] Krusell, P., Martin, F. M., Rios-Rull, J.-V., 2006, Time-consistent debt, Mimeo.

[12] Lucas, R. E., Stokey, N. L., 1983, Optimal fiscal and monetary policy in an economy without capital, Journal of Monetary Economics, 12, 55-93

[13] OECD, 2009, OECD in figures

[14] Ricardo, D., 1951a, On the principles of political economy and taxation, The works and correspondence of David Ricardo, Cambridge university press, vol 1 
[15] Ricardo, D., 1951b, Funding System, The works and correspondence of David Ricardo, Cambridge university press, vol 4 